\title{
SOME CONSTRAINTS ON HIGH SCHOOL STUDENTS' MATHEMATICS PERFORMANCE: AWI-ZONE \& WEST- GOJAM, ETHIOPIA
}

\author{
Adem Mohammed Ahmed
}

\author{
Bahir Dar University, Ethiopia
}

ademahmed192@gmail.com

\author{
First draft received: 12 Oct $2017 \quad$ Accepted: 29 Dec $2017 \quad$ Final proof received: 5 Feb 2018
}

\begin{abstract}
This study was designed to examine the possible constraints that can affect high school students' mathematics performance in five selected high schools in Awi-zone and west- Gojam. Observations and reports from examining bodies revealed that a high percentage of secondary school students continue to perform poorly in mathematics examinations. From a total of forty high schools, five were selected using simple random sampling technique. The respective sections were selected using purposive sampling techniques. Four sections were selected from each school. Then, 250 samples of students were employed using comprehensive sampling technique. To obtain data, questionnaire, classroom observation, and semi-structured interviews were used. 50 students from each school were selected using simple random sampling technique for the questionnaire. Similarly, three teachers from each of the sample school were selected using simple random sampling technique for the questionnaire, classroom observation and interview. The quantitative data were analyzed using one sample $t$-test whereas the qualitative one was analyzed using descriptive interpretations. The findings showed that students have laid claim on the problem of scoring passing mark as a result of poor mathematics performance. In addition, the result indicates that teachers possess the theories and their application of indirect instruction, organizing mathematics lessons, classroom management using assessment techniques. The findings also implied that there are opportunities to improve students' performance in mathematics in the high schools to the expected level. Furthermore, the findings showed that paraphrasing math word problems improves performance of some students. In relation to the findings of the study, recommendations are forwarded.
\end{abstract}

Keywords: Constraints; Ethiopia; high school students; mathematics performance

To cite this paper (in APA style):

Ahmed, A.M. (2018). Some constraints on high school students' mathematics performance: Awi-Zone \& West- Gojam, Ethiopia. International Journal of Education, 10(2), 114-120. doi: http://dx.doi.org/

\section{INTRODUCTION}

Obe (1996) conceptualized mathematics as the master and servant of most fields and thus a source of enlightenment and understanding of the universe. He further states that without mathematics, the understanding of national problems would be unrealistic. In connection, Setidisho (2001) presented that no other subject forms a strong adhering force among diverse subdivisions of science as mathematics, and without mathematics, knowledge of science often remains unrealistic. Education in science and mathematics, therefore, becomes fundamental principle and essential tool for scientific, technological and economic progress in any country. It gives a nation the capacity to utilize technology for the exploitation of the resources of universe. It is well described in the literature that affective variables have strong influence on mathematics learning and achievement.
Main factors linking the disadvantages to underachievement can be thematically classified into a deficiency of positive environment and support (Banergee, 2016). The frequency with which a student is present in the class, the trait of being well-behaved, and achievement differences are all very strongly correlated (Alsace, 2009; Graber, 2010).

According to Mousoulides \& Philippou (2005), selfefficacy is a strong forecaster of academic performance in mathematics. Meanwhile, Schenkel (2009) maintained that attitudes towards mathematics represent a like or dislike of the subject and they embrace beliefs, abilities, and views on the usefulness of mathematics.

On the same note, according to Kebritchi, Hirumi, \& Bai (2010), students' mathematics apprehensions and skills improved as a result of playing mathematics games. According to the teachers, the games were efficient teaching and learning instruments because 
they: (a) had an experiential nature, (b) extended an alternative way of teaching and learning, (c) afforded the students reasons to learn mathematics to solve the game problems and progress in the games, (d) decreased students' mathematics phobia, and (e) increased time on activity. On the other hand, according to the students, the games were efficient because they (a) mixed learning and fun, (b) proposed mathematics in adventurous and explorative context, and (c) challenged students to learn mathematics. In addition, the majority of the students expressed that they preferred playing multi-player versus single-player games. Thus, collaborative nature of the games made the games more attractive for students to play.

On the other hand, mathematics anxiety is one factor that affects student achievement (Zakaria, Zain, Ahmad, \& Erlina, 2012). Therefore, teachers should strain to understand mathematics anxiety and implement teaching and learning strategies so that students can get the better of their anxiety. Researchers of mathematics anxiety verifies that it has been reasonably responsible in taking over test anxiety's theoretical foundation for mathematics anxiety (Hembree, 1990). Maloney, Schaeffer, \& Beilock (2013) identified the negative effects of students' anxiety on assessments of mathematics proficiency and have presented that, for many students' mathematics tests are capturing far more than their mathematics knowledge.

Thus, student behavior and teacher guided classroom management positively correlates with student achievement (Marsden, 2006). There are some grounds that teacher's effects are more marked for mathematics achievement in high minority schools Konstantopoulos \& Chung (2011).

Furthermore, it was found that teacher qualification and student environment did not influence students' poor performance; however, teaching methods have shaped poor performance of students in general mathematics and further mathematics (Gegbe \& Koroma, 2014). Teachers should thus promote and motivate students to love mathematics related subjects. Students must formulate positive attitude towards the teacher and the subject matter. It is a fact that teacher factor, students attitude and commitment, methods of teaching mathematics, use of instructional materials and the school environment are to a great extent valid factors that influence students' poor performance in mathematics in the senior secondary school certificate examination in Kogi state, Nigeria (Umameh, 2011). This is so because as noted by Brown (2016), rational mathematical thought necessarily leans on beliefs set within a play of ideological framings within school partition in terms of their stakeholder interface with mathematics.

Meanwhile, according to Peak (2011), improving the academic achievement of students who are often in the middle or average scope and who are mainly minorities and are economically disfavored has been shown to bring about significant improvement in mathematics achievement. OECD (2016) has distinguished typical individual, family, regional, and school level components linked with differential attainment in mathematics and science. McLeod (1992) identified three concepts used in his research that affect mathematics education: beliefs, attitudes, and emotions. He made distinctions among these and described emotions as the most intense and least stable, beliefs as the most stable and least intense, and attitudes as somewhere in between on both dimensions. Beliefs were seen as the most 'cognitive' and emotions as the least so.

Gherasim, Butnaru, and Mairean (2013) observed gender factors in such variables as achievement goals, classroom environments and achievement in mathematics among young adolescents indicating that girls received higher grades in mathematics than boys. Significant gender differences were found in attitudes towards mathematics. More boys than girls read mathematics "outside readers", took part in mathematics extracurricular activities and consulted reference books when encountering difficulty in mathematics.

Another research found that amount of homework time, the act of teaching at school of the parents and residential size had nothing to do with attitude, learning habit and academic achievement (Wong, 1992). On the other hand, Daw (2012) proposed that the amount of homework and the socio-economic achievement gap in mathematics and science are directly proportional in secondary school. It can be expected that the student may not have enough support at home. The employments of focused instructional materials in school are thus further supported. Degree of affection of mathematics also deteriorated as students ascended the grade levels, and many students found mathematics lessons tiresome. Although most students liked mathematics, they considered it as a crucial subject and were unforced to give attempt to learn mathematics outside school, many of them did not have selfconfidence in learning mathematics. According to Burstein (1992), students' attitude towards mathematics and their performances and achievements are directly proportional to each other. Therefore, those students having positive attitude do better than holding negative attitude concerning mathematics (Gibbons, Kimmel, \& O'Shea, 1997).

So far, in another study by the use of episode writing, "ability to solve mathematics problems", "having the correct answers", "accurate and fast solution", "ability to apply to daily life situations", "knowing the underlying principle", "understanding the procedure and strategies", "ability to clarify concepts", "knowing the relationships among concepts" and "ability to explain to others" were some of the indicators of understanding as comprehended by the students (Wong, 1995).

Observations and reports from examining bodies in the context of the present research revealed that a high percentage of secondary school students continue to perform poorly in mathematics examinations. According to Ministry of Education of Ethiopia (2015), only $27 \%$ of the secondary students' school performance levels in 2014/15 met the standard, level 3. Furthermore, according to the Education Bureau of 
Amhara region, where the research took place, by 2016 only approximately $33 \%$ of students who took grade 10 national exams in the region obtained the passing mark (50\%).

Despite the laudable efforts at developing an acceptable general mathematics curriculum, students' performance in the subject appears to be declining over the years. Meanwhile, schools are established to accomplish specific goals and objectives and incidentally one of the most common criteria of evaluating the effectiveness of any school system is the extent to which the students perform in their examinations. Thus, the objectives of this study are to examine the factors responsible for the students' poor performance in mathematics in selected secondary schools. Specifically, it will examine teachers' and students' attitude to teaching and learning of mathematics, the nature of school environment, teachers' teaching methods, and teachers' use of instructional materials and finally to recommend the concerned body for its remedy.

According to Agirdag, van Houtte, \& van Avermaet (2012), more than one-level studies of data grounded on a study of 2,845 pupils (aged between 10 and 12 years) in 68 Flemish primary schools disclosed that a higher proportion of migrant and working-class pupils in a school is related with lower levels of math achievement in both migrant and indigenous Belgian students. The authors' findings determined that the ethnic composition of the school no longer had a substantial effect on students' achievement, while the socio-economic status composition did.

A significant forecaster of achievement in mathematics is the teacher's communication of objectives and expectations. Earlier research (Gherasim et al., 2013) has demonstrated the grandness of knowing the goals of an activity for being productive. It is also sensible to believe that if we know what we are looking for, it should be more comfortable to find it. The outcomes of this study demonstrated a positive relationship between the factor-properly communicated objectives-and achievement in mathematics.

\section{METHOD}

Basically, quantitative data analysis technique was used to analyze the data and qualitative analysis technique was also used as a supplement to the quantitative data analysis. To see the extent to which the perceived constraints affect the mathematics performance of students, one sample $t$-test analysis was applied. The data drawn from observation and interview were thematically analyzed qualitatively using descriptions.

The research designs used in this study were survey research design and analytical research design. Moreover, the research approach used in the study was a quantitative approach supported or complemented by a qualitative research approach.

\section{Participants}

The study was designed to explore factors of perceived constraints on students' performance in mathematics.
Specifically, this study was designed to examine the effect of perceived constraints on five high school students in mathematics. Moreover, this research further aimed to discover the relationship between beliefs and performance of mathematics. In addition, the effects of some factors that teachers identified as constraining students' poor performance in mathematics were intensively investigated.

To this end, the target population of the study was high school students and mathematics instructors in West Gojam and Awi zones, Amhara regional state, Ethiopia. From a total of nine functioning high schools, five high schools were selected using simple random sampling technique. The five high schools' respective mathematics teachers were selected using purposive sampling techniques. Then, all mathematics teachers of the five high schools selected using comprehensive sampling technique were samples of this study. Fifty students from each of the five high schools were selected using simple random sampling technique for questionnaire and similarly three mathematics teachers from each of the sample high school were selected using simple random sampling technique for questionnaire, observation and interviewing.

\section{Data Gathering Instruments}

In this study, questionnaire, classroom observation, and semi-structured interviews were used as the basic instruments for collecting data. Questionnaire including both close ended and open ended questions that encompasses questions of different variables was used as the main data gathering tool. The close ended questions were 5- point Likert scale questions whereas open ended questions request teachers to describe a recently used problem, explain why they prefer particular types of questions, identify opportunities and constraints of teaching in mathematics classes in their respective high schools and describe the professional development needs of the staff at their school in relation to the implementation of good teaching-learning approaches.

Furthermore, the semi-structured interview and observation guides were designed in such a way that they provide relevant data that helped us to answer the basic research questions of this study.

\section{FINDINGS AND DISCUSSION}

This part deals with the analysis of results obtained from the questionnaire distributed to students and teachers of the five high schools situated in Gojam and Awi- zone, Amhara Regional state, Ethiopia. 250 students were involved in filling the questionnaire. The questionnaire of the students constitutes 20 items categorized under three themes. The questionnaire of the teachers constitutes 25 items categorized under one theme. One sample $t$-test was employed to examine students' poor performance in mathematics and teachers' mathematical knowledge, practice and level of support. The findings are presented, analyzed and interpreted as follows: 
Table 1: Test anxiety of students:

\begin{tabular}{|c|c|c|c|c|c|}
\hline Variables & $\begin{array}{l}\text { Expected } \\
\text { mean }\end{array}$ & Observed mean & sd & df & Sig \\
\hline Inferior than other classmates & 3 & 2.4 & .665 & 249 & $.000^{*}$ \\
\hline $\begin{array}{l}\text { Keep thinking of questions that I cannot answer in } \\
\text { previous part }\end{array}$ & 3 & 2.6 & .802 & 249 & $.000^{*}$ \\
\hline Think about the consequence of failing in the exam & 3 & 2.3 & .459 & 249 & $.000^{*}$ \\
\hline $\begin{array}{l}\text { Feel nervous and worry } \\
\text { Cannot remember what I have learnt before }\end{array}$ & $\begin{array}{l}3 \\
3\end{array}$ & $\begin{array}{l}3.5 \\
3.1\end{array}$ & $\begin{array}{l}.672 \\
1.303\end{array}$ & $\begin{array}{l}249 \\
249\end{array}$ & $\begin{array}{l}.000^{*} \\
.226\end{array}$ \\
\hline
\end{tabular}

significant at alpha value of $0.05 ; n=250$

The results in Table 1 portray that there was a significant mean difference between the expected (3) and the observed (2.4) regarding that in taking math exam, students had negative thought that they were inferior to other classmates which was in favor of the expected mean.

This implies that students had bad experience of feeling inferiority concerning math exam. Similarly, table 1 shows that there was a significant difference between the expected (3) and the observed (2.6) regarding that students kept thinking about questions that they could not answer. The same is true for thinking about the consequence of failing and feeling nervous and worry in the exam. However, one of the categories that were observed in this study was that whether they can remember what they have learned before the exam or not. As the responses obtained from the students disclosed, there was no significant difference between the expected mean (3) and the observed mean (3.1). This implies that the students' remembrance only did not help them in answering questions in a mathematics examination.

Table 2: Perception of students on the influence of teachers' method of teaching and learning materials on students' poor academic performance:

\begin{tabular}{lrrrrr} 
Variables & $\begin{array}{c}\text { Expected } \\
\text { mean }\end{array}$ & $\begin{array}{c}\text { Observed } \\
\text { mean }\end{array}$ & \multicolumn{1}{c}{ sd } & df & Sig \\
\hline Large class size & 3 & 3.1 & 1.303 & 249 & .082 \\
Teachers are not innovative in methodology & 3 & 2.5 & .501 & 249 & $.032^{*}$ \\
Instructional materials are not provided for the teachers & 3 & 2.5 & 1.027 & 249 & .065 \\
Inadequate lesson plan & 3 & 3.4 & 1.202 & 249 & .076 \\
Inadequate supervision & 3 & 3.2 & .750 & 249 & $.047^{*}$ \\
\hline
\end{tabular}

significant at alpha value of $0.05 ; n=250$

The results in table 2 show that there was a significant difference between means of teachers' not being innovative in methodology, expected mean (3) and observed mean (2.5), and inadequate

supervision, expected mean (3) and observed mean (3.2). However, there was no significant difference between the expected mean and observed mean of large class size, not providing instructional materials, and inadequate lesson plan.

Table 3: Perception of students on their poor academic performance and teachers' qualifications:

\begin{tabular}{lccccc}
\hline Variables & $\begin{array}{c}\text { Expected } \\
\text { mean }\end{array}$ & $\begin{array}{c}\text { Observed } \\
\text { mean }\end{array}$ & sd & df & Sig \\
\hline Lack of quality teachers & 3 & 2.5 & 1.027 & 249 & .000 \\
$\begin{array}{l}\text { Most teachers do not have adequate knowledge of } \\
\text { their subject }\end{array}$ & 3 & 2.45 & .776 & 249 & $.000^{\circ}$ \\
Extreme dependence on text books & 3 & 3.6 & .918 & 249 & $.000^{*}$ \\
Lack of professional development & 3 & 3.1 & .832 & 249 & .059 \\
Inadequate teaching skills & 3 & 3.4 & 1.116 & 249 & $.000^{*}$ \\
Teachers' inadequate salary & 3 & 3.0 & .776 & 249 & 1.00 \\
\hline
\end{tabular}

significant at alpha value of $0.05 ; n=250$

The results in table 3 shows that there was a significant difference between the mean of lack of quality teachers, expected mean (3) and observed mean (2.5); extreme dependence on text books, expected mean (3) and observed mean(3.6); and inadequate teaching skills expected mean (3) and observed mean(3.4). Moreover, there was a significant difference between the expected mean (3) and observed mean (2.45) of having no adequate knowledge of their subject. However, lack of professional development and teachers' inadequate 
salary did not have significant difference between the expected mean and observed mean.

As it is expected, the current finding was consistent with findings of previous studies. Silverman and Thompson (2008), for example, explained that instructors' practices are affected by their own experiences as learners of mathematics as well as by their experiences in classroom teaching as instructors' of mathematics.

This study explored whether and how teachers' mathematical knowledge for teaching contributes to enhancing students' mathematics achievement. It was found that teachers' mathematical knowledge was significantly related to student achievement gains in high school grades.

The present study had clear limitations, including the small sample of students and teachers, missing data, and a lack of alignment between our measure of teachers' mathematical knowledge and student achievement. These problems may bias the effect size coefficients of our content knowledge for teaching variable toward zero, however, we feel confident that the positive effects observed in our analyses were robust and, if anything, underestimated. However, we are less confident in any borderline or null results, such as those found for the teacher preparation measures. Therefore, the researcher focused his concluding discussion primarily on the effects of the content knowledge variable on students' achievement. It was found that teachers' mathematical knowledge for teaching positively predicted student gains in mathematics achievement in high schools. Moreover, the positive effect on student gains in the high schools suggests that teachers' content knowledge plays a role even in the teaching of very elementary mathematics content.

An important feature of these analyses was that the researcher measured mathematical knowledge for teaching, not simply teachers' computational facility or course taking. Consequently, it has been difficult to measure reliably or validly on a large scale. In this work, it has been attempted to build on these scholars' theories about relationships of subject matter and pedagogy by designing a measure of teachers' mathematical knowledge for teaching, and hence it can be reported that this more task-sensitive measure is positively related to student achievement.

The results modify interpretations of earlier studies exploring the effect of teachers on student achievement (Hanushek, 1997). In one hand, they support Shulman's (1986) important critical review of the process-product literature, namely, that studying teacher impact in light of subject-specific behavior is critical. Moreover, the findings help visualize a new generation of processproduct studies designed to answer questions about how teachers' mathematical behavior-in particular, their classroom explanations, representations, and interactions with students' mathematical thinking - might affect student outcomes. The results of this study also inform findings from the educational production function literature by indicating that a direct measure of teachers' content knowledge for teaching horns placeholder measures such as courses taken or experience and by suggesting that measures of teacher knowledge should be at least content specific or, even better, specific to the knowledge used in teaching children. The findings of this study both support and challenge recent policy initiatives. If successful, efforts to improve teachers' mathematical knowledge through content-focused professional development and pre-service programs will improve student achievement, as intended.

\section{CONCLUSIONS}

Training should be given to mathematics teachers in different types of skills (Intellectual, Teaching, Evaluation etc.) to foster the students' performance. Teachers should enrich the students through effective open-ended questions, communication process, organization of mathematics related co-curricular activities, creative discussions, genuine experimentation etc.

In the same line, awareness should be given to parents in the way they could help students to foster their mathematical performance informally and at times non- formally. Schools need to arrange some special programs for development of mathematics performance. Teachers and school heads need to create conducive environment in schools for improving mathematics performance and its development.

Meanwhile, in order for schools to become more effective via producing more effective Mathematics teachers, some quandaries were found. Some teachers expressed that many of the students in the upper secondary level have a fallible background of basic Mathematics skills. Some teachers also indicated that students' interest in learning Mathematics was the primary problem. One teacher had even boldly and confidently declared that many students dislike intense Mathematics. A few teachers remarked the grandness of continuous Professional Development on teaching Mathematics. However, the findings of this study proposed that the teachers' professional development experiences were not very powerful in arriving at positive changes on either the teachers' practices or their beliefs. It is clear from the study that effectiveness of classroom instruction originates from the teacher. Mathematics teachers have to be well-prepared, wellknowledgeable, and extremely supported for modifications in the curriculum and instructional strategies to occur. A special pedagogy noticed in the model teacher that surpassed from the others was the teacher's calling into question abilities. The teacher was not only an explorer (the teacher rationalized what to do by explaining how and why the operation works), he was also a questioner (the teacher requires the students to be able to develop the procedure themselves). Suffolk (2007) connoted that the explainer is teacher-centered, while the questioner is learnercentered. On the other hand, Wong (2007) indicated that the teacher involves being the main figure in the Mathematics classroom, and not the students. It is the teacher who plans learning activities, which are the fundamental to understanding. The teacher needs to guide the classroom and its learning activities (Tsang et 
al., 2014). Therefore, one characteristic of efficient classrooms might be teacher-led, yet student-centered. This is in line with Khalid's argument (2006) that effective teaching demands teachers to determine: "what aspects of a task to highlight, assessment techniques that enhance performance into the learning of mathematics, how to organize and direct the work of students, what questions to ask students having varied levels of expertise, and how to support students without taking over the process of [mathematical] thinking for them" (p. 176).

Based on the findings of the study, the following recommendations were forwarded: The curriculum developers, implementers and educational evaluators and school heads should enforce teachers to apply appropriate teaching methods. Teachers need to

\section{REFERENCES}

Agirdag, O., van Houtte, M.

$\&$ van Avermaet, P. (2012). Why does the ethnic and socio-economic composition of schools influence math achievement? The role of sense of futility and futility culture. European Sociological Review, 28, 366378. 366378.10.1093/esr/jcq070

Alsace, T. O. (2009). What makes a difference in the academic performance in English language arts and mathematics for Puerto Rican English language learners with and without disabilities? Pro Quest Information \& Learning, 69.

Brown, T. (2016). Rationality and belief in learning mathematics. Educational Studies in Mathematics, 92(1), 75-90. https://doi.org/10.1007/s10649-015-9670-7

Burstein, L. (1992). The analysis of multilevel data in educational research and evaluation. Review of Research in Education, 8, 158- 223. Federal Republic of Nigeria 2004: National Policy on Education (Revised), NERC.

Daw, J. (2012). Parental income and the fruits of labor: Variability homework efficacy in secondary school. Research in Social Stratification and Mobility, 30, 246264.10.1016/j.rssm.2012.01.004

Ethiopian Ministry of Education. (2015). Education Sector Development Program V (ESDP V) 2015/16-2019/20. Addis Ababa.

Gegbe, B., \& Koroma, J. . (2014). Students and teachers' perception of the causes of poor academic performance in general and further mathematics in Sierra Leone: A case study of BO District Sourthern Province. International Journal of Engineering Research and General Science, 2(5), 240-253.

Gherasim, L.R., Butnaru, S., Mairean, C. (2013). Classroom environment, achievement goals and maths performance: Gender differences. Educational Studies, 39, 1-12. doi: 10.1080/03055698.2012.663480

Gibbons, S., Kimmel, H., \& O'Shea, M. (1997). Changing teacher behaviour through development: Implementing the teaching and content identify mathematically creative students and forming the teaching group for their improvement of mathematics performance. Schools have to arrange special provisions and arrangements for counseling of mathematically creative talents. Creativity should be made Compulsory and integrated in all primary and secondary school mathematics curriculum, scheme of work, lesson note, lesson plan and in the classroom when teaching and learning take place. The Ministry of Education should review the Teacher Education programs for the development of some mechanism for improving mathematics performance. The Ministry of Education should review its programs to improve the capacity of the prospective teachers.

standards in science. School Science and Mathematics, 97(6), 302-310 .

Graber, C. R. (2010). Factors that are predictive of student achievement outcomes and an analysis of these factors in high-poverty schools versus low-povertyschools. ProQuest Information \& Learning, 71.

Hanushek, E. A. (1997). Assessing the effects of school resources on student performance: An update. Educational evaluation and policy analysis, 19(2), 141-164.

Hembree, R. (1990). The nature, effects and relief of mathematics anxiety. Journal for Research in Mathematics Education, 21(1), 33-46. https://doi.org/10.2307/749455

Kebritchi, M., Hirumi, A., \& Bai, H. (2010). The effects of modern mathematics computer games on mathematics achievement and class motivation. Computers and Education, 55(2), 427-443. https://doi.org/10.1016/j.compedu.2010.02.007

Khalid, M. (2006). Mathematical thinking in Brunei curriculum: Implementation issues and challenges. 169-178. Progress report, " Collaborative Studies on Innovations for Teaching and Learning Mathematics in Different Cultures (II)-Lesson Study focusing on Mathematical Thinking-". CRICED: University of Tsukuba

Konstantopoulos, S., \& Chung, V. (2011). Teacher effects on minority and disadvantaged students' grade 4 achievement. The Journal of Educational Research, 104, 73.

86.10.1080/00220670903567349

Maloney, E. A., Schaeffer, M. W., \& Beilock, S. L. (2013). Mathematics anxiety and stereotype threat: Shared mechanisms, negative consequences and promising interventions. Research in Mathematics Education, 15(2), 115128.

https://doi.org/10.1080/14794802.2013.797744

Marsden, D. B. (2006). Relations between teacher perceptions of safe and orderly environment and student achievement among ten betterperforming, high-poverty schools in one Southern California elementary school district. ProQuest Information \& Learning, 67. 
McLeod, D.B. (1992). Research on affect in mathematics education: A reconceptualization.In D.A. Grows (Ed.), Handbook of research on mathematics teaching and learning (pp.575-596). New York:Macmillan.

Mousoulides, N., \& Philippou, G. (2005). Students' Motivational Beliefs, Self-Regulation Strategies and Mathematics Achievement. Proceedings of the 29th Conference of the International Group for the Psychology of Mathematics Education, 3, 321-328.

Obe, E. O. (1996). Remedies for Mass Failure and Examination Malpractices. In E.O. Obe (Ed), School Indiscipline and Remedies. Lagos Premier Press ad Publishers.

OECD. (2016). Low performing students: Why they fall behind and how to help them succeed. PISA. Paris. doi:10.1787/9789264250246-en.

Banergee, P. A. (2016). A systematic review of factors linked to poor academic performance of disadvantaged students in science and maths in schools. Cogent Education, 3(1), 1178441.

Peak, D. J. (2011). A correlational study of the advancement via individual determination (AVID) program with middle school student achievement in mathematics. ProQuest Information \& Learning, 71.

Salam, N. H. A., \& Shahrill, M. (2014). Examining classroom interactions in secondary mathematics classrooms in Brunei Darussalam. Asian Social Science, 10(11), 92-103.

Schenkel, B. (2009). The impact of an attitude towards Mathematics on Mathematics performance. (Master's dissertation). Marietta College, Ohio, USA. Retrieved from: https://etd.ohiolink.edu/ap/10?0::NO:10:P10_AC CESSION_NUM:marietta1241710279.

Setidisho, A. W. (2001). The validity of beliefs about factors related to mathematics achievement. A paper presented at the Annual Meeting of the American Educational Research Association, Chicago, U.S.A.

Shulman, L. S. (1986). Those who understand: Knowledge growth in teaching. Educational Researcher, 15(2), 4-14.

Silverman, J., \& Thompson, P.W. (2008). Toward a framework for the development of mathematical knowledge for teaching. Journal of Mathematics Teacher Education, 11, 499-511.

Suffolk, J. (2007). Making the teaching of Mathematics more effective. Paper presented at the Proceedings of the Redesigning Pedagogy: Culture, Knowledge and Understanding Conference, Singapore. Retrieved from http://conference.nie.edu.sg /2007/paper/papers/MAT685.pdf

Tsang, H. M. V., Mohammad Malik Finti, H. N. F., \& Shahrill, M. (2014). The leadership styles of secondary mathematics teachers in Brunei Darussalam. In F. Uslu (Ed.), Abstracts and Proceedings of the International Conference on Social Sciences and Humanities (pp. 923-931). Istanbul, Turkey: International.Organization Center of Academic Research, OCERINT.

Umameh, M. A. (2011). a Survey of factors responsible for students'poor performance in mathematics in senior secondary school certificate examination (ssce) in idah local government area of kogi state, nigeria. Retrieved from http://www.academia.edu/7671293/a_survey_of_ factors_responsible_for_students_poor_perform ance in mathematics_in_senior_secondary_sch ool_certificate_examination_ssce_in_idah_local_ government_area_of_kogi_state_nigeria

Wong, N. Y. (2007). Hong Kong teachers' views of effective Mathematics teaching and learning. ZDM The International Journal ofMathematics Education, 39(4), 301-314.

Wong, N.Y. (1992). The relationship among mathematics achievement, affective variables and home background. Mathematics Education ResearchJournal, 4, 32-42.

Wong, N.Y. (1995). The relationship between Hong Kong students' perception of their mathematics classroom environment and their approaches to learning: A longitudinal study (Unpublished Ph.D. thesis). The University of Hong Kong, Hong Kong.

Zakaria, E., Zain, N. M., Ahmad, N. A., \&Erlina, A. (2012). Mathematics anxiety and achievement among secondary school students. American Journal of Applied Sciences, 9(11), 1828-1832. https://doi.org/10.3844/ajassp.2012.1828.1832 